\title{
«r+d in Life Sciences» \\ Vertrauen und Sympathie, die Basis für gute Geschäftsbeziehungen
}

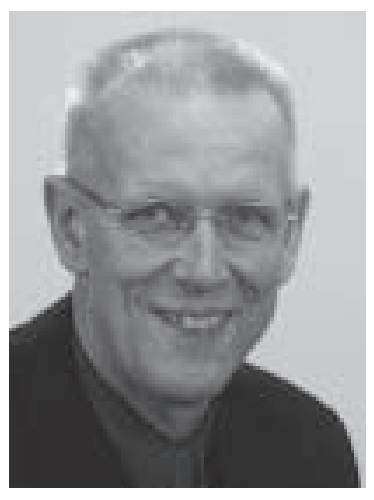

Liebe Leserin, lieber Leser,

'Braucht es heute eigentlich noch Messen? Braucht es eine neue Messe wie die «r+d in Life Sciences»? Die modernen Kommunikationsmittel ermöglichen es doch, unabhängig von Ort und Zeit Informationen auf dem ganzen Globus auszutauschen. Sie machen eine Messe überflüssig.'

Solche oder ähnliche Fragen bzw. Aussagen hört man immer wieder. Ich kann Ihnen darauf eine simple Antwort geben: Es braucht die Messen, weil sie als Marketinginstrument für eine gezielte Marktbearbeitung eine Vielzahl von Qualitäten in sich vereinen, die sich schlicht nicht ersetzen lassen. Dabei ist festzustellen, dass der soziale Aspekt an Bedeutung gewinnt. Denn viele Geschäftspartner haben realisiert, dass für langfristig erfolgreiche Geschäftsbeziehungen der persönliche Kontakt - und dazu ist die Messe die ideale Plattform - eine Vertrauensbasis schafft. Insbesondere bei neu anzubahnenden Geschäftskontakten ist es wichtig, ein Klima des Vertrauens zu schaffen, was über Internet oder virtuelle Messen nicht möglich ist.

Die Veränderungen im Markt und der Bedürfnisse der Anwender hat uns dazu bewogen, die ehemalige Chemiemesse «ilmac» durch die « $r+d$ in Life Sciences», welche erstmals vom 15.-18. Oktober 2002 in Basel stattfindet, zu ersetzen. Bei all unseren strategischen Überlegungen war es für uns nie ein Thema, die Existenz der Messe als Marketinginstrument zu hinterfragen. Denn die Messe mit ihrem anspruchsvollen Angebotsspektrum in Forschung und Entwicklung ist das direkte Bindeglied zwischen Anbietern und ihren Zielmärkten in Industrie und Wissenschaft. Viele Fachleute werden sich an der « $r+d$ in Life Sciences» kennen lernen und Gespräche führen, die oft der Beginn einer langjährigen intensiven Zusammenarbeit sind. Die Grundlage dafür ist gegenseitiges Vertrauen und Sympathie. Diese Basis kann nur durch den direkten persönlichen Kontakt - Face-to-Face - geschaffen werden.

In diesem Sinne wünsche ich Ihnen bereits heute viele neue geschäftliche Verbindungen mit interessanten Menschen: An der «r+d in Life Sciences», 15.-18. Oktober 2002 in Basel.

Ueli Blaser

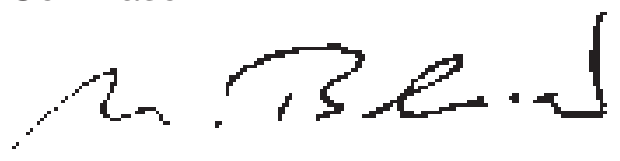

Messeleiter « $r+d$ in Life Sciences»

ueli.blaser@messe.ch 